\title{
Dietary linoleic acid at high and reduced dietary fat level decreases the faecal excretion of vitamin $E$ in young rats
}

\author{
BY LILIAN B. M. TIJBURG, EDWARD HADDEMAN, GERARD A. A. KIVITS, \\ JAN A. WESTSTRATE AND ELIZABETH J. BRINK \\ Unilever Research Laboratory, PO Box 114, 3130 AC Vlaardingen, The Netherlands
}

(Received 15 March 1996 - Revised 18 June 1996 - Accepted 15 July 1996)

\begin{abstract}
Vitamin $\mathbf{E}$ is the major lipid-soluble antioxidant in human subjects and is crucial in protecting polyunsaturated fatty acids (PUFA) against lipid peroxidation. Dietary PUFA have been suggested to inhibit the absorption of vitamin $E$. The present study in young male rats was designed to investigate the effect of increasing concentrations of dietary linoleic acid on the faecal excretion of vitamin $E$. The rats were fed on semi-synthetic diets containing two concentrations of fat $(59 \mathrm{~g} / \mathrm{kg}$ diet, 15 energy \% (en\%) or $131 \mathrm{~g} / \mathrm{kg}, 30 \mathrm{en} \%$ ) for 3 weeks. Triacylglycerol rich in linoleic acid was added at the expense of triacylglycerol rich in saturated fatty acids to obtain dietary concentrations of 13,39 or $66 \mathrm{~g}$ linoleic acid/ $\mathrm{kg}$ diet for the high-fat diet $(131 \mathrm{~g}$ fat $/ \mathrm{kg})$ and 12,24 or $36 \mathrm{~g}$ linoleic acid $/ \mathrm{kg}$ diet for the reduced-fat diet $(59 \mathrm{~g}$ fat $/ \mathrm{kg}$ ). The results from the present study demonstrate that the faecal excretion of vitamin $\mathbf{E}$ was significantly lower in rats fed on diets with high levels of linoleic acid compared with rats fed on lower levels of linoleic acid irrespective of the dietary fat content. The concentration of vitamin $E$ in liver and plasma was significantly lower in animals fed on the highest concentration of linoleic acid compared with those fed on the lowest level. Results from the present study also demonstrate that at the same concentration of linoleic acid, the faecal excretion of vitamin $\mathbf{E}$ in rats fed on reduced-fat diets was significantly lower than in rats fed on high-fat diets. Our findings indicate that the apparent absorption of vitamin $\mathbf{E}$ is not inhibited by dietary PUFA. Results from the present study also demonstrate that a reduction of dietary fat content from 30 en\% to 15 en\% does not lower the apparent absorption of vitamin $E$.
\end{abstract}

Linoleic acid: Vitamin E: Rats

Oxidative damage of polyunsaturated fatty acids (PUFA) and DNA has been associated with the development of degenerative diseases such as cardiovascular disease and cancer (Ames, 1983; Steinberg et al. 1989). Biological antioxidants play an important role in protecting PUFA against peroxidation reactions. Vitamin $\mathrm{E}$ is one of the most efficient chain-breaking biological antioxidants and is located in membranes and lipoproteins in the vicinity of PUFA (Burton, 1990). Dietary vitamin $\mathrm{E}$ is passively absorbed together with dietary lipids in the upper part of the small intestine. A vital step for the absorption of vitamin $\mathrm{E}$ and other fat-soluble vitamins is the digestion of dietary lipids and the formation of mixed micelles composed of monoacylglycerols, fatty acids, bile salts and phospholipids (Björneboe et al. 1990; Kayden \& Traber, 1993). Incomplete hydrolysis or absorption of dietary lipids may impair the micellar uptake of fat-soluble vitamins (Kuksis, 1987).

It is generally accepted that an increased intake of PUFA should be accompanied by an increased consumption of vitamin $\mathrm{E}$ to compensate the elevated vitamin $\mathrm{E}$ demand in cell membranes and lipoproteins (Jager \& Houtsmuller, 1970; Horwitt, 1974). The effect of linoleic acid (18:2n-6) on the vitamin $E$ absorption in rats has been investigated previously using radiolabelled $\alpha$-tocopherol (Weber et al. 1964; Green et al. 1967; Gallo-Torres et al. 
1971). Data from these studies indicate that PUFA decrease vitamin $E$ absorption either by interfering directly with the absorption process or reducing the available amount of vitamin E due to degradation in the intestinal tract (Weber et al. 1964; Green, 1967; Gallo-Torres et al. 1971). However, interpretation of these experiments is hampered by the fact that artificial fat mixtures were used containing linoleic acid either as free fatty acid or as methyl ester rather than linoleic acid-rich triacylglycerols. The presence of linoleic acid as free fatty acid or methyl ester may alter the formation of mixed micelles in the small intestine which is crucial for vitamin $\mathrm{E}$ absorption. Dietary triacylglycerol, in contrast to free fatty acids, gives rise to the formation of lipolytic products, e.g. monoacylglycerol and free fatty acids, which are thought to be important for the absorption of vitamin E (Traber et al. 1993).

The present study was undertaken to assess in a systematic way the influence of the concentration of dietary linoleic acid, incorporated in triacylglycerol as normally consumed in the diet, on the apparent absorption (defined as intake minus excretion) and liver concentration of vitamin $E$. Therefore, the effect of three different concentrations of dietary linoleic acid on the faecal excretion of vitamin $E$ was investigated in rats with adequate vitamin $\mathrm{E}$ intake. An additional objective of the present study was to assess whether a significant reduction in the level of dietary fat would affect vitamin $E$ absorption. As outlined previously the absorption of vitamin $\mathrm{E}$ may also be dependent on the amount of fat in the diet and, hence, may be impaired at lower dietary fat concentrations. This may eventually lead to lower vitamin $\mathrm{E}$ concentrations in tissues and lipoproteins and an increased risk of oxidative damage. To also investigate the effect of reducing the level of fat in the diet on vitamin $E$ absorption, we used two different dietary fat levels, high-fat $(131 \mathrm{~g} / \mathrm{kg}, 30$ energy $\%(\mathrm{en} \%))$ or reduced-fat diets $(59 \mathrm{~g} / \mathrm{kg}, 15 \mathrm{en} \%)$.

\section{MATERIALS AND METHODS}

The experimental protocol was approved by the Animal Welfare Officer and the Animal Experimentation Committee of Unilever Research Laboratory, Vlaardingen

\section{Animals and housing}

Seventy-two male Wistar rats (Hsd/Cpb;WU, Harlan, Zeist, The Netherlands), aged about 6 weeks, were used. The animals were housed individually in wire-mesh-bottomed cages under standard conditions (temperature $22-24^{\circ}$, relative humidity $45-65 \%$ and day-night cycles of $12 \mathrm{~h}$ ). The animals were divided into six dietary groups of twelve animals each and were fed on the experimental diets for 3 weeks.

\section{Experimental diets}

During the acclimation period the animals consumed a semi-synthetic diet containing $131 \mathrm{~g}$ fat $/ \mathrm{kg}$ diet. Vitamin $\mathrm{E}$ was added to this diet as $\alpha$-tocopheryl acetate (Roche, Basel Switzerland) in a concentration of $30 \alpha$-tocopherol equivalents $(\alpha$-TE, where $1 \mathrm{mg} \mathrm{D}-\alpha$ tocopheryl acetate is equivalent to $0.67 \alpha-\mathrm{TE}$ ) $/ \mathrm{kg}$ diet. The experimental diets contained either $59 \mathrm{~g}$ or $131 \mathrm{~g}$ fat $/ \mathrm{kg}$ diet. The composition of the diets is given in Table 1 . At each dietary fat level three concentrations of linoleic acid were used. Fat blends with the appropriate concentration of linoleic acid, added in the form of triacylglycerols, were prepared by mixing varying amounts of cocoa butter, sunflowerseed oil, safflower oil and Trisun high-oleic acid oil (Contined, Bennekom, The Netherlands). To obtain the range of linoleic acid concentrations, linoleic acid-rich triacylglycerol was increased at the expense 
Table 1. Composition $(\mathrm{g} / \mathrm{kg})$ of experimental diets fed to rats

\begin{tabular}{|c|c|c|c|c|c|c|}
\hline \multirow{2}{*}{$\begin{array}{l}\text { Dietary fat }(g / \mathrm{kg}) \ldots \\
\text { Linoleic acid }(\mathrm{g} / \mathrm{kg}) \ldots\end{array}$} & \multicolumn{3}{|c|}{59} & \multicolumn{3}{|c|}{131} \\
\hline & 12 & 24 & 36 & 13 & 39 & 66 \\
\hline \multicolumn{7}{|l|}{ Ingredient } \\
\hline Calcium caseinate & 213 & 213 & 213 & 237 & 237 & 237 \\
\hline Mineral mixture* & 12.5 & 12.5 & 12.5 & 13.9 & 13.9 & 13.9 \\
\hline Vitamin mixture* & 2.9 & 2.9 & 2.9 & 3.2 & 3.2 & 3.2 \\
\hline Maize starch & 660 & 660 & 660 & 557 & 557 & 557 \\
\hline Cellulose & 52 & 52 & 52 & 58 & 58 & 58 \\
\hline Experimental fat: & 59 & 59 & 59 & 131 & 131 & 131 \\
\hline Saturates & 26.9 & $16 \cdot 1$ & 6.3 & 74.2 & 48.0 & 21.8 \\
\hline Monounsaturates & $20 \cdot 2$ & 19.6 & $20 \cdot 1$ & 43.7 & 43.7 & 43.7 \\
\hline Polyunsaturates & 11.9 & 23.2 & 32.6 & 13.1 & 39.3 & 65.5 \\
\hline \multicolumn{7}{|l|}{ Chemical analysis } \\
\hline Fat & 63 & 65 & 68 & 140 & 138 & 136 \\
\hline$\alpha$-Tocopherol (mg) & 43.0 & 43.5 & 43.3 & $46 \cdot 1$ & 48.7 & 49.7 \\
\hline
\end{tabular}

*Mineral mixture (mg/g mineral mixture): $\mathrm{KCl} 96 \cdot 72, \mathrm{MgHPO}_{4} .3 \mathrm{H}_{2} \mathrm{O} 264 \cdot 20, \mathrm{KH}_{2} \mathrm{PO}_{4} 131 \cdot 27, \mathrm{KHCO}_{3} 198 \cdot 70$, $\mathrm{CaCO}_{3} 81.52$, sodium citrate $.2 \mathrm{H}_{2} \mathrm{O} 196 \cdot 49$, $\mathrm{MnSO}_{4} \cdot \mathrm{H}_{2} \mathrm{O} 14 \cdot 20$, ferric citrate $.5 \mathrm{H}_{2} \mathrm{O}(190 \mu \mathrm{g} / \mathrm{mg}) 12 \cdot 13$, copper citrate $(350 \mu \mathrm{g} / \mathrm{mg}) 1.30$, zinc citrate $(320 \mu \mathrm{g} \mathrm{Zn} / \mathrm{mg}) 3.45, \mathrm{KIO}_{3} 0.02$. Composition of the vitamin mixture (mg/g): choline chloride $597 \cdot 5$, myo-inositol 29.9 , nicotinamide $6 \cdot 0$, cyanocobalamin $15 \cdot 5$, thiamin $1 \cdot 8$, calcium pantothenate 6.0 , riboflavin 1.8 , pyridoxine 1.9 , folic acid 0.3 , menadione 1.2 , biotin 0.06 , retinyl palmitate 9.2 , cholecalciferol $3 \cdot 0$, calcium silicate 59.75 , sucrose 266.09 .

of triacylglycerol rich in saturated fatty acids (mainly palmitic and stearic acid). To obtain reduced-fat diets, dietary fat was exchanged for carbohydrates on an isoenergetic basis. Reduced-fat diets ( $59 \mathrm{~g}$ fat $/ \mathrm{kg}, 15 \mathrm{en} \%$ from fat) contained either 12,24 or $36 \mathrm{~g}$ linoleic $\mathrm{acid} / \mathrm{kg}$ (3, 6 or $9 \mathrm{en} \%)$ as triacylglycerol. The linoleic acid concentrations used in the high-fat diet (131 g fat $/ \mathrm{kg}, 30 \mathrm{en} \%$ from fat) were 13,39 or $66 \mathrm{~g} / \mathrm{kg}(3,9,15 \mathrm{en} \%)$. Diets with similar dietary fat content but different linoleic acid content were similar with respect to all other dietary components. The analysed fatty acid composition of the diets is shown in Table 2. D- $\alpha$-tocopherol (Sigma, St Louis, MO, USA) was added to the fat mixtures to obtain dietary vitamin $\mathrm{E}$ concentrations of 44 and $49 \alpha$-TE/ $\mathrm{kg}$ diet for the reduced-fat and high-fat diet respectively (3.0 $\propto \mathrm{TE} / \mathrm{MJ})$.

\section{Experimental design}

During a $7 \mathrm{~d}$ acclimation period the rats consumed a semi-purified diet ad libitum. After this period the animals consumed the experimental diets for 3 weeks. Throughout the experiment food and drinking water were freely available. Body-weight measurements and clinical observation were carried out once weekly. Food consumption was recorded throughout the experiment. In the third experimental week faeces for vitamin $E$ analysis were collected for four consecutive days for each rat separately. At the end of the experiment the animals were deprived of food for $16 \mathrm{~h}$. Blood was collected in EDTAcoated tubes by aorta puncture while rats were anaesthetized with halothane. The animals were killed by decapitation and a piece of tissue from the medial liver lobe was removed for vitamin $\mathrm{E}$ analysis. 
Table 2. Analysed fatty acid distribution ( $\mathrm{g} / 100 \mathrm{~g}$ total fatty acids) of the experimental diets fed to rats*

\begin{tabular}{|c|c|c|c|c|c|c|}
\hline \multirow{2}{*}{$\begin{array}{l}\text { Dietary fat ... } \\
\text { Linoleic acid }(\mathrm{g} / \mathrm{kg}) \ldots \\
\text { Fatty acid }\end{array}$} & \multicolumn{3}{|c|}{ High-fat $(131 \mathrm{~g} / \mathrm{kg})$} & \multicolumn{3}{|c|}{ Reduced-fat $(59 \mathrm{~g} / \mathrm{kg})$} \\
\hline & 13 & 39 & 66 & 12 & 24 & 36 \\
\hline $14: 0$ & $0 \cdot 1$ & 0.1 & 0.1 & 0.1 & 0.1 & 0.1 \\
\hline $16: 0$ & $22 \cdot 1$ & $15 \cdot 1$ & 7.9 & 18.7 & 11.8 & 6.0 \\
\hline $16: 1$ & 0.3 & 0.2 & 0.1 & 0.2 & 0.2 & 0.1 \\
\hline 18:0 & 31.7 & $19 \cdot 3$ & 6.8 & 25.4 & 13.3 & 3.3 \\
\hline $18: 1 n-9$ & 33.6 & $33 \cdot 3$ & 33.0 & 33.7 & $33 \cdot 3$ & 33.2 \\
\hline $18: 2 n-6$ & 10.4 & $30 \cdot 2$ & 50.1 & $20 \cdot 0$ & $39 \cdot 6$ & 55.4 \\
\hline $18: 3 n-3$ & 0.1 & 0.2 & 0.2 & 0.2 & 0.1 & 0.1 \\
\hline $20: 0$ & $1 \cdot 0$ & 0.7 & 0.4 & 0.9 & 0.6 & 0.4 \\
\hline Total & 99.3 & $99 \cdot 1$ & 98.6 & 99.2 & 99.0 & 98.5 \\
\hline
\end{tabular}

*The fatty acid distribution of the experimental diets was determined by GC analysis; for details, see p. 331 .

\section{Measurement of $\alpha$-tocopherol in experimental fats, faeces, plasma and liver}

Experimental fats. A portion of the fat blends was dissolved in chloroform-propan-2-ol $(1: 2, v / v)$. The samples were injected onto a reversed-phase $C 18$ column $(250 \times 4.6 \mathrm{~mm}$, $5 \mu \mathrm{m}$; Merck, Darmstadt, Germany), eluted with methanol-propan-2-ol-water (50:50:6, by vol.) and monitored with u.v. detection at $292 \mathrm{~nm}$. Vitamin E was quantified using D,L$\alpha$-tocopherol as external standard.

Plasma and liver. $\alpha$-Tocopherol was extracted from plasma as described previously using $\alpha$-tocopheryl acetate as internal standard (Catignani, 1986). Following extraction, the sample was injected onto a reversed phase C18 column $(250 \times 4.6 \mathrm{~mm}, 5 \mu \mathrm{m}$; Merck) and eluted with methanol-propan-2-ol-water (50:50:6, by vol.). The eluent was monitored with a UV-Vis detector set at 292 ( $\alpha$-tocopherol) and $284 \mathrm{~nm}$ ( $\alpha$-tocopheryl acetate). The concentration of $\alpha$-tocopherol was calculated from the relative peak areas using extinction coefficients of 75.8 and 43.6 for $\alpha$-tocopherol and $\alpha$-tocopheryl acetate respectively.

Immediately after killing, a piece of liver was homogenized in ethanol-water $(90: 10$, $\mathrm{v} / \mathrm{v}$ ) containing $0.1 \mathrm{~g}$ ascorbic acid and $0.002 \mathrm{~g}$ pyrrogallol/1. The homogenate was extracted with $n$-heptane containing $\alpha$-tocopheryl acetate as internal standard. $\alpha$-Tocopherol was quantified by HPLC as described previously (Farwer et al. 1994).

Faeces. Faeces for $\alpha$-tocopherol analysis were collected during $4 \mathrm{~d}$ at $8.00,10.00$, $13.30,17.00,20.00$ and 23.00 hours. The faeces from each animal were combined in $25 \mathrm{ml}$ methanol-water $(1: 1, \mathrm{v} / \mathrm{v})$ containing butylated hydroxytoluene $(1 \mathrm{~g} / 1)$ and kept at $0-4^{\circ}$. The combined faeces were stored at $-20^{\circ}$ until required for extraction. After thawing, the faeces were homogenized in $n$-heptane containing D,L- $\delta$-tocopherol as internal standard. The heptane extract was analysed by HPLC on a Lichrospher 100 Diol column $(250 \times 4.0 \mathrm{~mm}, 5 \mu \mathrm{m}$; Merck), eluted with $n$-heptane-propan-2-ol (1000:7, v/v). The eluent was monitored by fluorimetric detection at an emission wavelength of $330 \mathrm{~nm}$ and excitation wavelengths of 294 and $298 \mathrm{~nm}$ for $\alpha$ - and $\delta$-tocopherol respectively. The concentration of $\alpha$-tocopherol was calculated from the relative peak areas of $\alpha$ - and $\delta$ tocopherol using external standard curves. 


\section{Other analytical methods}

Dietary fat was extracted with dichloromethane using a Soxtec apparatus (Tecator, Höganäs, Sweden) and determined gravimetrically. The fatty acid composition of the diets was determined by capillary GC following transmethylation in methanol-BF 3 . Fatty acid methyl ester analysis was carried out as described previously (Brink et al. 1995) on a CP$9000 \mathrm{GC}$ with flame-ionization detection, using a fused silica Megabore DB-225 column (30 m $\times 0.55 \mathrm{~mm}, 1.0 \mu \mathrm{m} ; \mathrm{J} \& \mathrm{~W}$ Scientific, Folson, CA, USA). Cholesterol was determined spectrophotometrically in EDTA plasma on a Cobas Mira S analyser (Roche, Basel, Switzerland) using an enzymic kit from Boehringer (Mannheim, Germany).

\section{Statistical analysis and calculations}

Data are reported as means with their standard errors ( $n$ 12), unless indicated otherwise. The apparent absorption was calculated as intake minus excretion of vitamin $E$ during the $4 \mathrm{~d}$ period of faeces collection and was expressed on that basis and as percentage of the intake. The cumulative energy intake was calculated from the food intake over the first $17 \mathrm{~d}$ of the experimental period using energy contents of 16.18 and $14.53 \mathrm{~kJ} / \mathrm{g}$ diet for the high-fat and reduced-fat diets respectively. Statistical analysis was carried out with the Statistical Analysis Systems (1987) statistical package. The data were analysed by ANOVA. For each dietary fat concentration the effects of linoleic acid were determined with Fisher's least significant difference test. Differences between high-fat and reduced-fat diets were also established with ANOVA using only linoleic acid concentrations which were similar at both fat levels, e.g. 3 and 9 en\%. The level of significance was pre-set at $P<0.05$.

\section{RESULTS}

\section{Food consumption and body-weight gain}

The different concentrations of dietary linoleic acid did not significantly affect food consumption or body-weight gain (results not shown). The cumulative food consumption over $17 \mathrm{~d}$ was significantly higher in animals fed on a reduced-fat diet compared with a high-fat diet (281 (SE 5.1) g ( $n$ 36), v. 263 (SE 5.8) g; $P<0.01$ ). The calculated cumulative intake of energy of animals fed on the high-fat diet was slightly but statistically significantly higher than that of animals fed on the reduced-fat diets (4.278 (SE 0.073) MJ v. 4.042 (SE 0.044) MJ ( $n$ 36); $P<0.01$ ). Body weights $(\mathrm{g})$ at the start of the experimental period were 136 (SE 2.8), 136 (SE 2.7) and 136 (SE 2.7) respectively for rats fed on a highfat diet containing 13,39 , or $66 \mathrm{~g}$ dietary linoleic acid $/ \mathrm{kg}$. For rats fed on the reduced-fat diet with 12,24 or $36 \mathrm{~g}$ linoleic acid $/ \mathrm{kg}$, the initial bodyweights (g) were 135 (SE 3.1), 136 (SE 2.6) and 135 (SE 2.7) respectively. Body-weight gain (g) during the experimental period of $20 \mathrm{~d}$ was 118 (SE 4.6), 102 (SE 4.0) and 109 (SE 5.1) respectively for rats fed on a high-fat diet with 13, 39 or 66 g linoleic acid per kg diet and 108 (SE 5.3), 118 (SE 5.5) and 109 (SE 5.4) for rats fed on the reduced-fat diets. There was no significant difference between body-weight gains of animals fed on the high-fat and those fed on the reduced-fat diet.

\section{Intake and faecal excretion of vitamin $E$}

Influence of linoleic acid. There was no difference in vitamin $\mathrm{E}$ intake between the experimental groups (Table 3). In rats fed on a high-fat diet the excretion of vitamin $E$ significantly decreased with increasing concentrations of dietary linoleic acid (Table 3). In rats fed on high-fat diets the vitamin $\mathrm{E}$ excretion was approximately $40 \%$ lower when 
Table 3. Effect of linoleic acid and dietary fat concentration on the intake, faecal excretion and apparent absorption of $\alpha$-tocopherol of young rats $\dagger$

(Mean values with their standard errors for twelve rats)

\begin{tabular}{|c|c|c|c|c|c|c|c|c|}
\hline \multicolumn{3}{|c|}{ Diet composition } & \multicolumn{6}{|c|}{ Vitamin E } \\
\hline \multirow[t]{2}{*}{ Fat } & \multicolumn{2}{|c|}{ Linoleic acid } & \multicolumn{2}{|c|}{ Intake (mg/4 d) } & \multicolumn{2}{|c|}{$\begin{array}{l}\text { Faecal excretion } \\
\text { (mg/4 d) }\end{array}$} & \multicolumn{2}{|c|}{$\begin{array}{c}\text { Apparent absorption } \\
\text { (\% intake) }\end{array}$} \\
\hline & $\mathrm{g} / \mathrm{kg}$ & en\% & Mean & SE & Mean & SE & Mean & $\mathrm{SE}$ \\
\hline High-fat & $\begin{array}{l}13 \\
39 \\
66\end{array}$ & $\begin{array}{r}3 \\
9 \\
15\end{array}$ & $\begin{array}{l}3 \cdot 137 \\
2.867 \\
3.029\end{array}$ & $\begin{array}{l}0.078 \\
0.061 \\
0.077\end{array}$ & $\begin{array}{l}0.666^{\mathrm{a}} \\
0.497^{\mathrm{b}} \\
0.399^{\mathrm{c}}\end{array}$ & $\begin{array}{l}0.049 \\
0.030 \\
0.030\end{array}$ & $\begin{array}{l}78 \cdot 7^{\mathrm{a}} \\
82 \cdot 7^{\mathrm{b}} \\
86 \cdot 6^{\mathrm{c}}\end{array}$ & $\begin{array}{l}1.74 \\
0.98 \\
1.20\end{array}$ \\
\hline Reduced-fat & $\begin{array}{l}12 \\
24 \\
36\end{array}$ & $\begin{array}{l}3 \\
6 \\
9\end{array}$ & $\begin{array}{l}2.969 \\
3 \cdot 158 \\
2.984\end{array}$ & $\begin{array}{l}0.086 \\
0.080 \\
0.059\end{array}$ & $\begin{array}{l}0.365^{\mathrm{d} * * *} \\
0.264^{\mathrm{e}} \\
0.208^{\mathrm{e} * * *}\end{array}$ & $\begin{array}{l}0.032 \\
0.024 \\
0.011\end{array}$ & $\begin{array}{l}87 \cdot 8^{\mathrm{d}_{* * *}} \\
91 \cdot 6^{\mathrm{e}} \\
93 \cdot 0^{\mathrm{e} * * *}\end{array}$ & $\begin{array}{l}0.98 \\
0.74 \\
0.44\end{array}$ \\
\hline
\end{tabular}

$a, b, c, d, e$ Mean values within a column at the same dietary fat concentration with different superscript letters were significantly different (Fisher's least significant difference test; $P<0.05$ ).

en\%, energy $\%$.

Mean values were significantly different from those for the high-fat diet with the same linoleic acid content (expressed as en $\%$ ): $* * * P<0.001$.

$\dagger$ For details of animals and procedures, see pp. 328-330.

†High fat, $131 \mathrm{~g}$ fat $/ \mathrm{kg}$ diet (30 en\%); reduced fat, $59 \mathrm{~g}$ fat $/ \mathrm{kg}$ diet $(15 \mathrm{en} \%)$. For details of diets see Tables 1 and 2.

animals were fed on diets with the highest linoleic acid concentration compared with those fed the lowest concentration of linoleic acid (cf Table 3; $P<0.001$ ). Similar effects of dietary linoleic acid were found when rats were fed on a reduced-fat diet.

The apparent absorption of $\alpha$-tocopherol (expressed as $\%$ intake) significantly increased as the dietary linoleic acid concentration increased (Table 3 ). This effect was more pronounced in rats fed on high-fat diets compared with those fed on reduced-fat diets.

Influence of dietary fat. The excretion of $\alpha$-tocopherol was significantly higher in rats fed on high-fat diets compared with those fed on reduced-fat diets containing similar linoleic acid concentrations $(P<0.001$; Table 3$)$. As a consequence, the apparent absorption (\%) of $\alpha$-tocopherol was significantly lower in animals receiving high-fat diets than in those fed on reduced-fat diets $(P<0.001$; Table 3$)$.

\section{Liver and plasma vitamin $E$ concentration}

Influence of linoleic acid. As shown in Figure 1 (a) an increase in the dietary linoleic acid concentration from $13 \mathrm{~g} / \mathrm{kg}$ diet $(3 \mathrm{en} \%)$ to $39 \mathrm{~g} / \mathrm{kg}$ (9 en\%) significantly reduced the hepatic vitamin $\mathrm{E}$ concentrations in animals consuming a high-fat diet $(P<0.001)$. Further increasing the dietary linoleic acid concentration did not significantly affect the hepatic vitamin E concentration (Fig. 1). In animals fed on a reduced-fat diet the hepatic volume $E$ concentration at the highest linoleic acid concentration $(36 \mathrm{~g} / \mathrm{kg})$ was significantly lower than at the lowest linoleic acid concentration $(12 \mathrm{~g} / \mathrm{kg}$ diet $)$.

Plasma vitamin E concentrations were standardized for plasma cholesterol concentrations (Horwitt et al. 1972). There was no difference in the plasma concentrations of total cholesterol between the groups. Fig. 1 (b) demonstrates that in animals fed on a high-fat diet the vitamin $\mathrm{E}$ concentration in plasma significantly decreased with increasing dietary 

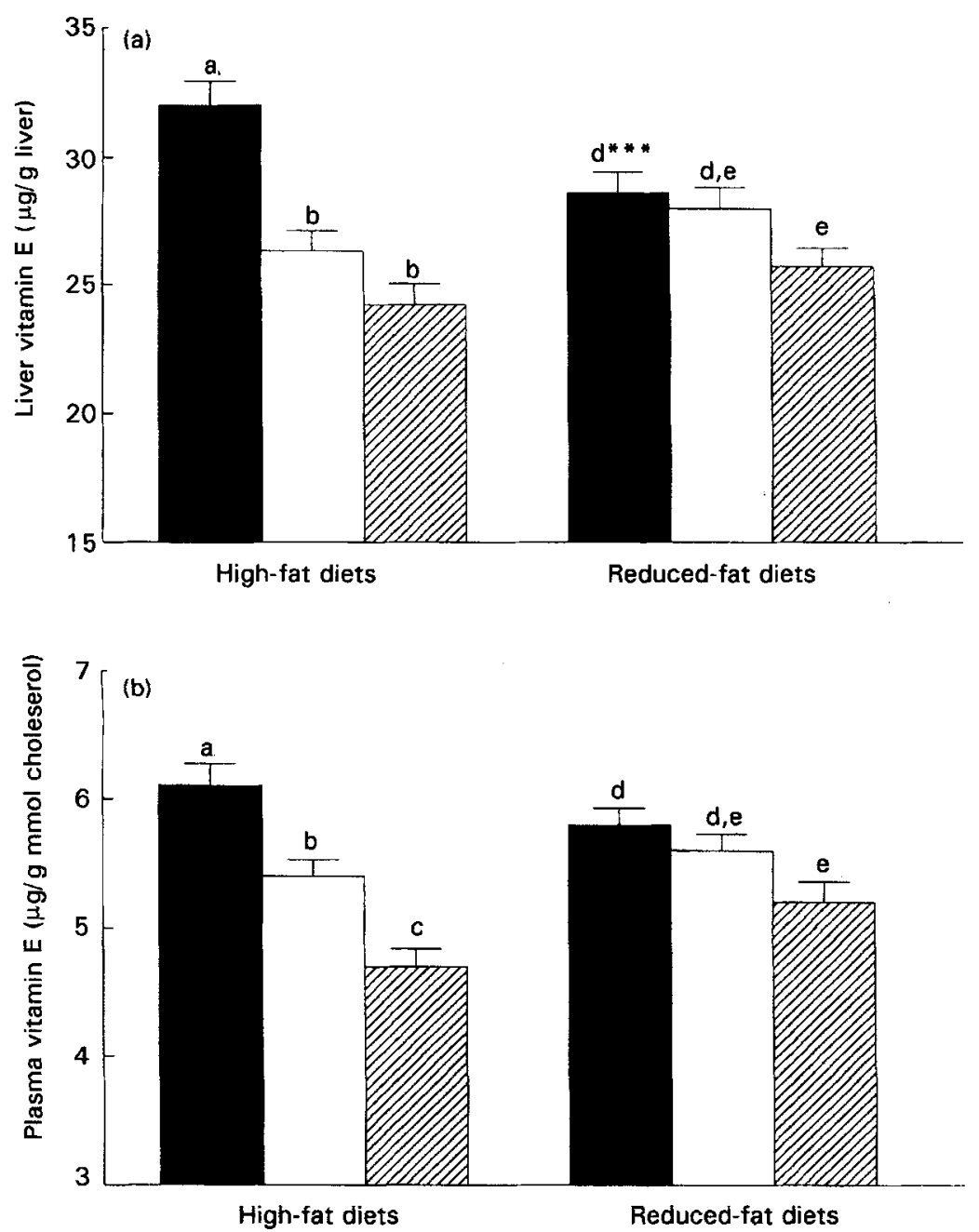

Fig. 1. Effect of dietary fat and linoleic acid content on hepatic and plasma vitamin $\mathbf{E}$ concentrations in young rats. (a), $12 \mathrm{~g}$ linoleic acid $/ \mathrm{kg}(3$ energy $\%(\mathrm{en} \%)$ ) for reduced-fat diets and $13 \mathrm{~g}$ linoleic acid $/ \mathrm{kg}(3 \mathrm{en} \%$ ) for high-fat diets respectively; ( $\square$ ), $24 \mathrm{~g} / \mathrm{kg}$ (6 en\%) for reduced-fat diets and $39 \mathrm{~g} / \mathrm{kg}(9 \mathrm{en} \%$ ) for high-fat diets respectively; (河), $36 \mathrm{~g} / \mathrm{kg}(9 \mathrm{en} \%)$ for reduced-fat diets and $66 \mathrm{~g} / \mathrm{kg}(15 \mathrm{en} \%)$ for high-fat diets respectively. (a), Liver vitamin $\mathrm{E}$ concentration; (b), plasma vitamin $\mathrm{E}$ concentration. Values are means with their standard errors represented by vertical bars for twelve rats. For details of diets, see Tables 1 and 2 and for details of animals and procedures, see pp. 328-330;

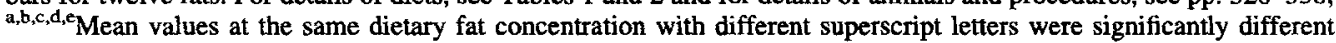
(Fisher's least significant difference test; $P<0.05$ ). Mean value was significantly different from that for rats fed on a high-fat diet containing $13 \mathrm{~g}$ linoleic acid $\mathrm{kg}(3 \mathrm{en} \%): * * * P<0.001$.

linoleic acid concentrations. As in liver, the reduction in the plasma concentration of vitamin $\mathrm{E}$ at increasing dietary linoleic acid concentrations was more pronounced in rats fed on high-fat diets $(131 \mathrm{~g} / \mathrm{kg})$ compared with those fed on reduced-fat diets $(59 \mathrm{~g} / \mathrm{kg})$.

Influence of dietary fat. In rats consuming a diet with linoleic acid at $3 \mathrm{en} \%$ the concentration of vitamin $\mathrm{E}$ in liver was significantly higher in rats fed on high-fat diets 
compared with those fed on reduced-fat diets (Fig. 1 (a)). However, no difference between high- and low-fat diets was observed with linoleic acid at 9 en\%. Dietary fat content did not significantly affect the concentration of vitamin $\mathrm{E}$ in plasma (Fig. 1 (b)).

\section{DISCUSSION}

The present study shows that an increased amount of dietary linoleic acid results in a significant reduction of the faecal excretion of vitamin $E$ (Table 3) in young male rats with adequate vitamin $E$ intake. After consumption of high-fat diets the concentration of vitamin $\mathrm{E}$ in liver and plasma significantly decreased with increasing concentrations of dietary linoleic acid (Fig. 1). In reduced-fat diets this effect was less pronounced.

An increased consumption of dietary PUFA results in a higher concentration of these fatty acids in tissues and of lipoproteins containing phospholipids, triacylglycerols and cholesteryl esters. Therefore, there is general agreement that an increased consumption of dietary PUFA should be accompanied by a higher intake of vitamin $E$ to protect the unsaturated fatty acids from lipid peroxidation (Horwitt, 1974; Traber et al. 1993). In addition to the greater systemic use of vitamin $E$, it has been suggested that high concentrations of dietary PUFA may reduce the bioavailability of vitamin $E$ either by a diminished uptake of this vitamin or by an increased oxidation in the intestinal tract (Weber et al. 1964; Green et al. 1967; Gallo-Torres et al. 1971).

In previous studies investigating the effect of dietary PUFA on vitamin $\mathrm{E}$ absorption and vitamin $E$ status as judged by plasma and tissue concentrations, vitamin E-deficient rats were used (Weber et al. 1964; Green et al. 1967). Although there is no evidence that vitamin $\mathrm{E}$ deficiency influences the absorption efficiency of this vitamin, extrapolation of these experiments to human subjects with adequate vitamin $\mathrm{E}$ intake is more appropriate when animal models used are fed the recommended amount of vitamin $E$.

In the present study we used young male rats with adequate vitamin $E$ intake. It is important to note that, in contrast to previous studies (Weber et al. 1964; Green et al. 1967; Gallo-Torres et al. 1971), different fatty acid compositions of the diets were achieved by the exchange of linoleic acid-rich triacylglycerol for triacylglycerol rich in saturated fatty acids (Table 2). Since the diets were similar with respect to all dietary components other than the fat composition, the observed effects can only be due to differences in the fat composition. Data from the present study show that increased amounts of dietary linoleic acid resulted in a significant reduction in the faecal excretion of vitamin $E$. It can not be excluded, however, that the observed effect is due to a decrease in dietary saturated fatty acids rather than an increase in linoleic acid (Table 2). Recently, Dougherty et al. (1995) showed that the faecal fatty acid excretion was significantly higher after consumption of stearate-rich diets compared with diets with low levels of stearate. When part of the vitamin $E$ remains trapped in the indigestible lipid fraction of stearate-rich diets, it is no longer available for absorption. To investigate the hypothesis that the observed effects were due to differences in the level of dietary saturated fatty acids rather than linoleic acid, we carried out a small pilot experiment with similar design to that of the present study (L. B. M. Tijburg, E. Haddeman, G. A. A. Kivits, J. A. Weststrate and E. J. Brink, unpublished results). In this study the animals received a high-fat diet $(131 \mathrm{~g} / \mathrm{kg})$ and the concentration of triacyglycerols rich in linoleic acid (13 and $66 \mathrm{~g}$ linoleic acid $/ \mathrm{kg}$ diet) was increased at the expense of triacylglycerols rich in monounsaturated fatty acids (mainly oleic acid). Data from this pilot study showed that increasing the level of linoleic acid at the expense of monounsaturated fatty acids also resulted in a reduction of the faecal 
excretion of vitamin $\mathrm{E}$. This indicates that the observed effects are caused by linoleic acid and cannot be explained by alterations in the concentration of dietary saturated fatty acids.

The diminished excretion of vitamin $\mathrm{E}$ in rats fed on diets rich in linoleic acid may also be explained by an acceleration in the destruction of vitamin $\mathrm{E}$ in the intestinal tract in the presence of high concentrations of linoleic acid. Weber et al. (1964) observed that linoleic acid intake in rats did not affect tissue vitamin $E$ concentrations when radiolabelled vitamin $\mathrm{E}$ was administered intraperitoneally compared with peroral administration. It was also shown that linoleic acid had no effect on tissue or faecal vitamin E concentrations when interaction of this fatty acid with vitamin $E$ in the intestinal tract was avoided by feeding these compounds separately (Green et al. 1967). When vitamin E and dietary fatty acids were fed at the same time and interaction could take place, significantly less radioactive tocopherol was recovered in tissues from rats fed on linoleate compared with oleate. In the present study the observed reduction of the faecal excretion of vitamin $E$ in rats fed on linoleic-rich diets indicates that PUFA do not inhibit the apparent absorption of vitamin $\mathrm{E}$, but may increase the oxidative degradation of vitamin $\mathrm{E}$ in the gastrointestinal tract.

In agreement with previous studies (Mouri et al. 1984; Farwer et al. 1994), we found in the present study that the vitamin $E$ status was decreased in rats fed on high-fat diets containing higher levels of polyunsaturates (Fig. 1). As discussed previously this may be the result of a more rapid use of tocopherols to protect unsaturated lipids from lipid peroxidation in the gastrointestinal tract or tissues (Horwitt, 1974).

A surprising observation in the present study was that the faecal excretion of $\alpha$ tocopherol was significantly lower in rats fed on a reduced-fat diet $(59 \mathrm{~g}$ fat $/ \mathrm{kg}$ ) compared with a high-fat diet $(131 \mathrm{~g} / \mathrm{kg})$. Consequently, the apparent absorption of $\alpha$-tocopherol (defined as intake minus excretion) for the reduced-fat groups was higher than that for the high-fat groups (Table 3). We expected a lower or at least equal apparent absorption of this vitamin after consumption of low-fat diets compared with high-fat diets, since the absorption of vitamin $\mathrm{E}$ is a passive process requiring the presence of dietary fat in the intestinal lumen. It is conceivable that a minimum amount of fat is required for the formation of lipid micelles in which vitamin $E$ is incorporated before absorption. Our findings in the present study clearly show that a $50 \%$ reduction in dietary fat does not increase the excretion of vitamin $E$ (Table 3). This indicates that fat at $15 \mathrm{en} \%$ is sufficient for vitamin $E$ absorption in rats. The increased faecal excretion of vitamin $E$ in rats fed on high-fat diets compared with reduced-fat diets may be explained by different amounts of stearate in the diet. As outlined previously, the excretion of fat and probably also vitamin $\mathrm{E}$, is higher after consumption of stearate-rich diets compared with diets with low stearate levels. In high-fat diets containing linoleic acid at 3 and 9 en\% the absolute amount of stearic acid was 2 - and 4-fold higher respectively than that in reduced-fat diets with linoleic acid at the same en\%. This may result in a higher excretion of lipids in faeces after consumption of high-fat diets as compared with reduced-fat diets and consequently an enhanced faecal excretion of vitamin $E$.

In conclusion, the present study shows that increasing concentrations of dietary linoleic acid, administered as triacylglycerol, at the expense of triacylglycerol rich in saturated fatty acids, reduce the faecal excretion of vitamin E. This suggests that the absorption of this vitamin is not inhibited by dietary PUFA. However, this is not reflected by the observation that the hepatic and plasma concentration of vitamin $E$ decreased at increasing levels of dietary linoleic acid, which suggests an increased use of vitamin $E$ in vivo. Results from the present study also demonstrate that the apparent absorption of vitamin $\mathrm{E}$ from a reduced-fat diet containing fat at $15 \mathrm{en} \%$, was significantly higher than 
from a high-fat diet with fat at $30 \mathrm{en} \%$. It should be noted that the reduced-fat diet used in the present study still contained a significant amount of fat $(59 \mathrm{~g} / \mathrm{kg})$.

The authors would like to thank people from the Animal Care Department and I. M. van Benschop, J. A. Don, J. N. J. J. Mathot and W. G. L. van Nielen for technical assistance and $A$. Wiersma for statistical analysis.

\section{REFERENCES}

Ames, B. N. (1983). Dietary carcinogens and anticarcinogens. Oxygen radicals and degenerative diseases. Science 221, 1256-1264.

Björneboe, A., Björneboe, G. A. \& Drevon, C. A. (1990). Absorption, transport and distribution of vitamin E. Journal of Nutrition 120, 233-242.

Brink, E. J., Haddeman, E., De Fouw, N. J. \& Weststrate, J. A. (1995). Positional distribution of stearic acid and oleic acid in a triacylglycerol and dietary calcium concentration determines the apparent absorption of these fatty acids in rats. Journal of Nutrition 125, 2379-2387.

Burton, G. W. (1990). Vitamin E: antioxidant activity, biokinetics and bioavailability. Annual Review of Nutrition 10, 357-382.

Catignani, G. L. (1986). An HPLC method for the simultaneous determination of retinol and $\alpha$-tocopherol in plasma or serum. Methods in Enzymology 123, 215-219.

Dougherty, R. M., Allman, M. A. \& Iacono, J. M. (1995). Effects of diets containing high or low amounts of stearic acid on plasma lipoprotein fractions and fecal fatty acid excretion of men. American Journal of Clinical Nutrition 61, 1120-1128.

Farwer, S. R., Boer, B. C. J. de, Haddeman, E., Kivits, G. A. A., Wiersma, A. \& Danse, B. H. J. C. (1994). The vitamin $\mathrm{E}$ nutritional status of rats fed on diets high in fish oil, linseed oil or sunflowerseed oil. British Journal of Nutrition 72, 127-145.

Gallo-Torres, H. E., Weber, F. \& Wiss, O. (1971). The effect of different dietary lipids on the lymphatic appearance of vitamin E. International Journal of Vitamin \& Nutrition Research 41, 504-515.

Green, J., Diplock, A. T., Bunyan, J., McHale, D. \& Muthy, I. R. (1967). Dietary unsaturated fatty acid stress and the metabolism of $\alpha$-tocopherol in the rat. British Journal of Nutrition 21, 69-101.

Horwitt, M. K. (1974). Status of human requirement for vitamin E. American Journal of Clinical Nutrition 27, $1182-1193$.

Horwitt, M. K., Harvey, C. C., Dahm, D. H. \& Searcy, M. T. (1972). Relationship between tocopherol and serum lipid levels for determination of nutritional adequacy. Annals of the New York Academy of Sciences 203, 223-236.

Jager, F. C. \& Houtsmuller, U. M. T. (1970). Effect of dietary linoleic acid on vitamin E requirement and fatty acid composition of erythrocyte lipids in rats. Nutrition and Metabolism 12, 3-12.

Kayden, H. J. \& Traber, M. G. (1993). Absorption, lipoprotein transport, and regulation of plasma concentrations of vitamin $\mathrm{E}$ in humans. Journal of Lipid Research 34, 343-358.

Kuksis, A. (editor) (1987). Absorption of fat soluble vitamins. In Fat Absorption, pp. 65-86. Boca Raton, FL: CRC Press Inc.

Mouri, K., Ikesu, H., Ekasa, T. \& Igarashi, O. (1984). The influence of marine oil intake upon levels of lipids, $\alpha$-tocopherol and lipid peroxidation in serum and liver of rats. Journal of Nutritional Science and Vitaminology 30, 307-318.

Statistical Analysis Systems (1987). SAS/STAT Guide for Personal Computers, 6th ed. Cary, NC: SAS Institute Inc.

Steinberg, D., Parthasarathy, S., Carew, T. E., Khoo, J. C. \& Witzum, J. L. (1989). Beyond cholesterol. Modifications of low density lipoprotein that increase its atherogenicity. New England Journal of Medicine 320, 915-924.

Traber M. G., Cohn, W. \& Muller D. P. R. (1993). Absorption, transport and delivery to tissues. In Vitamin E in Health and Disease, pp. 35-51. [L. Packer and J. Fuchs, editors]. New York: Marcel Dekker Inc.

Weber, F., Weiser, H. \& Wiss, O. (1964). Bedarf an Vitamin E in Abhängigkeit von der zufuhr an Linolsäure (Vitamin E requirement as a function of linoleic acid supply). Zeitschrift fur Ernährungswissenschaft 4, 245253. 